\title{
A New Departure on Remote Island : A Case of Abalone Farming in Ehime, Japan
}

\author{
Jihoon Kim ${ }^{*}$ '1 Akira Nakayasu ${ }^{2}$, Naruhiho Takenouchi ${ }^{2}$ \\ ${ }^{1}$ The United Graduate of Agricultural Science, Ehime University, \\ Tarumi 3-5-7, Matsuyama 790-8566, Japan. \\ ${ }^{2}$ Department of Agricultural Economics and Agribusiness, Ehime University, Japan \\ ${ }^{2}$ Department of Agricultural Economics and Agribusiness, Ehime University, Japan \\ Email: stemi570826@yahoo.co.jp
}

\begin{abstract}
Japanese fish production is currently affected by two major currents: population ageing and lack of young leaders. I found a solution to resolve this problem which is the closed circulatory culture system on land. There is actual abalone farm that conducting these system in $\mathrm{OH}$ Island, Yahatahama City, Ehime Prefecture, Japan. Although there are many benefits of using this system, competitive price could be a problem. Abalone imports rapidly increased over decade and has encroached upon the abalone market in Japan. Therefore cost reduction is the most important task.
\end{abstract}

Keywords: Remote Island, Abalone Farming, Grants-in-Aid Program

\section{INTRODUCTION}

Japan is one of the greatest fisheries production nations in the world. Japan consists of four main islands and around 6000 large and small islands, and each individual island plays a significant role in marine products production, environment conservation, salvage, and borderline surveillance. However, Japan's fishery market is suffering due to the lack of new generation of fishery operators, decreasing the number for old generation fishermen because of retirement, consumers choosing western diet, and decreasing of marine products consumption, and this phenomenon stands out more in remote islands. Experts are predicting this phenomenon will affect negatively to the economy since there is not enough labors new generation - and the cost of shipment from remote island to capital cities are too expensive. Therefore, Japanese government's action is extremely critical to promote fishery production in remote islands. This study focused on $\lceil$ The closed circulatory culture system on land $\rfloor$ which was started via

$\lceil$ Grants-in-Aid Program to Vitalize Fishing Industry of Remote Island $\rfloor$ in $\mathrm{OH}$ Island, Yahatahama City, Ehime Prefecture, Japan and review outcome of this program. In addition, this study also investigates economic effects about abalone that is cultivated by the closed circulatory culture system.

\section{New challenge in Japan and $\mathrm{OH}$ Island}

\subsection{Outline of Ehime Prefecture and $\mathrm{OH}$ Island}

Japan consists of four main islands and around 6000 large and small islands. Shikoku is the smallest and least populous of the four main islands of Japan. Ehime Prefecture is a prefecture in northwestern Shikoku, Japan. The capital is Matsuyama. The fishery industry in Ehime is blessed with abundant marine resources and has been developing a coastal fishery and aquaculture. Red sea bream production is the highest in Japan at more than $50 \%$ of production nationwide. Yellowtail production is second highest in Japan. $\mathrm{OH}$ Island consists of five islands and located about 12 kilometers away from southwest of Yawatahama city. According to the government report, 64 percent of $\mathrm{OH}$ Island's total population is 65 or older which indicates that the rate is higher compare to other remote islands (33 percent).

Due to the fact that the aging population is constantly increasing and younger generation is not flowing in, elementary school and the middle school were not needed and shut down eventually in 2008. Fishing is OH Island's 
main industry since its ocean is pollution-free and marine resources are well preserved.

However, $\mathrm{OH}$ Island's fishing industry is expected to gradually decline because the average income from fisheries is around USD4,500 which is below than Japan`s fishery average earnings - USD16,000.

Table 1. Population structure of OH Island

\begin{tabular}{|c|c|c|c|}
\hline & Population & $\begin{array}{c}\text { Over } \\
\text { 65years }\end{array}$ & $\begin{array}{c}\text { Ratio of } \\
\text { Over } \\
65 \text { years }\end{array}$ \\
\hline 2008 & 343 & 202 & 58.89 \\
\hline 2009 & 324 & 200 & 61.73 \\
\hline 2010 & 310 & 195 & 62.90 \\
\hline 2011 & 303 & 190 & 62.71 \\
\hline 2012 & 296 & 186 & 62.84 \\
\hline 2013 & 288 & 188 & 65.28 \\
\hline 2014 & 275 & 177 & 64.36 \\
\hline
\end{tabular}

Source : Fishery Division in Yawatahama City

\subsection{Grants-in-Aid Program to Vitalize Fishing Industry of Remote Island}

Lack of transportation and infrastructure give a serious disadvantage of producing fisheries items and selling products to Remote Island (Takashi.T, 2012). In addition, the lack of new generation and graying cause reducing the roles of remote islands: marine products production, environment conservation, salvage, and borderline surveillance (Kudo T, 2012; Sasaki T, 2012). Therefore, Japanese government established a new $\lceil$ Grants-in-Aid Program to Vitalize Fishing Industry of Remote Island $」$ to increase productivity and rise income in remote island from 2005 (Takashi F, 2015). Grant in aid were paid around USD95,000,000 from 2005 to 2009 (the first period), around USD85,000,000 from 2010 to 2014 (the second period). OH Island was also subsidized around USD400,000 for the first period and started cultivation of abalone. However, around 40\% abalones have died from the high water temperature, red tide, and typhoon and shipments were falling behind $10 \%$. The cultivation of abalone was failed and make a new strategy was required for $\mathrm{OH}$ Island.
Table 2. Grants-in-Aid Program to Vitalize Fishing Industry of Remote Islands (JPY1,000)

\begin{tabular}{|c|c|c|c|}
\hline & Total & Ehime & $\begin{array}{c}\text { OH } \\
\text { Island }\end{array}$ \\
\hline $\begin{array}{c}2005 \\
- \\
2009\end{array}$ & $11,422,223$ & 340,936 & 48,960 \\
\hline $\begin{array}{c}2010 \\
- \\
2014\end{array}$ & $10,186,330$ & 305,728 & 39,304 \\
\hline Total & $21,608,553$ & 646,664 & 88,264 \\
\hline
\end{tabular}

Notes: Currency is Japanese Yen, $1 \mathrm{USD}=120 \mathrm{JPY}$

Source : Ministry of Agriculture, Forestry and Fisheries

\section{3 $\lceil$ The closed circulatory culture system on land $\lrcorner$}

The closed circulatory culture system on land has many advantages to control the underwater temperature which is more efficient for farming and reduces some obstacles related to predation, unlawfully hunt, temperature of water and weather conditions. However, this system needs a large area of land which is often difficult to find in a country like Japan (Rahman 2012) and high initial introduction cost like the equipment purchase will be a disadvantage of this system. $\mathrm{OH}$ Island got the grant and started abalone farming using that $\lceil$ The closed circulatory culture system on land $\rfloor$ from October 2012 and utilized a close-down school for the purpose of reducing manufacturing costs.

Table 3. Production effect of $\mathrm{OH}$ Island

\begin{tabular}{|c|c|c|}
\hline & 2014 & 2015 \\
\hline $\begin{array}{c}\text { Sales of } \\
\text { volume(kg) }\end{array}$ & 58.24 & 12.32 \\
\hline $\begin{array}{c}\text { Sales } \\
\text { figures(JPY) }\end{array}$ & 336,950 & 66,900 \\
\hline JPY/kg & $5,785.5$ & 5,430 \\
\hline
\end{tabular}

Source : Fishery Division in Yawatahama City 


\subsection{Rise of cost}

$\lceil$ The closed circulatory culture system

\section{The effect of the Land-Based Abalone Farming in $\mathrm{OH}$ Island}

\subsection{Unsuccessful of branding}

Many primary industry farmers are concerned about the crisis of agricultural markets owing to the opening of domestic markets through Free Trade, but the openness and globalization is inevitable. Individual farmers are trying to maximize revenue through branding in order to prepare them. Besides, Local governments make a strategy for brand development systems. In Ehime Prefecture, there are many branding products including Bochan abalone. Botchan is a novel written by Natsume Sōseki in 1906. It is one of the most popular novels in Japan, read by many Japanese during their school years. The story is based on the author's personal experience as a teacher dispatched to Matsuyama on the island of Shikoku. Finally Botchan became the representative character in Ehime. Botchan abalone is bigger than $\mathrm{Oh}$ island abalone and be farmed a better environment. Therefore Botchan abalone is getting recognize and popular in Ehime for the taste and freshness. However, Oh Islands abalone's sales will be decreased compare to last year.

\subsection{Uncompetitive price}

Japan imported abalone 1500 ton in 2013. And most of it was from Korea. Oh Island abalone has to compete with Korea abalone and other Japan abalone.

Table 4. Average wholesale price of abalone in Japan (JPY/kg)

\begin{tabular}{|c|c|c|c|}
\hline $\begin{array}{l}\text { Size per } \\
\text { piece }\end{array}$ & $\begin{array}{c}\text { Korea } \\
\text { Abalone } \\
\text { (farmed) }\end{array}$ & $\begin{array}{c}\text { Japan } \\
\text { Abalone } \\
\text { (natural) }\end{array}$ & $\begin{array}{c}\text { Oh } \\
\text { Island } \\
\text { Abalone }\end{array}$ \\
\hline $\begin{array}{l}\text { Over } \\
100 \mathrm{~g}\end{array}$ & 9,720 & 10,800 & \\
\hline $50 \sim 100 \mathrm{~g}$ & 5,264 & 5,480 & 5,430 \\
\hline $\begin{array}{l}\text { Under } \\
50 \mathrm{~g}\end{array}$ & 3,240 & 2,700 & \\
\hline
\end{tabular}
on land 」' $\mathrm{s}$ biggest problem is high costs of electricity, water and food for abalone. The original cost estimate around JPY626.9/piece in $\mathrm{OH}$ Island 2014. However Land-Based Abalone Farming breakeven point is estimated JPY600/piece in Japan. Moreover, the cost of Korea abalone is estimated JPY337.4/piece.

Table 5. The cost of abalone farming in $\mathrm{OH}$ Island(JPY)

\begin{tabular}{|l|c|c|}
\hline & 2013 & 2014 \\
\hline $\begin{array}{l}\text { Electric } \\
\text { charge }\end{array}$ & $\begin{array}{c}1,210,985 \\
(19.1)\end{array}$ & $\begin{array}{c}1,232,374 \\
(19.7)\end{array}$ \\
\hline Water charges & $\begin{array}{c}64,320 \\
(1.0)\end{array}$ & $\begin{array}{c}64,760 \\
(1.0)\end{array}$ \\
\hline Feed cost & $\begin{array}{c}139,584 \\
(2.2)\end{array}$ & $\begin{array}{c}158,623 \\
(2.5)\end{array}$ \\
\hline Labor costs & $\begin{array}{c}4,206,000 \\
(66.3)\end{array}$ & $\begin{array}{c}3,658,800 \\
(58.4)\end{array}$ \\
\hline Shellfish fry & $\begin{array}{c}634,250 \\
(10.1)\end{array}$ & $\begin{array}{c}1,097,250 \\
(17.5)\end{array}$ \\
\hline \multirow{2}{*}{ The others } & $\begin{array}{c}85,592 \\
(1.3)\end{array}$ & $\begin{array}{c}57,947 \\
(0.9)\end{array}$ \\
\hline \multirow{2}{*}{ Total } & $\begin{array}{c}6,340,731 \\
(100.0)\end{array}$ & $\begin{array}{c}6,269,754 \\
(100.0)\end{array}$ \\
\hline
\end{tabular}

Source : Fishery Division in Yawatahama City

\section{CONCLUSION}

Oh Island's abalone industry is expected to have a low impact on local economy from an economic standpoint. However, LandBased Abalone Farming will be continued and received Grant in Oh Island. Japan became an aging society in 1994, was swiftly passing through an aged society, and finally became a super-aged society in 2007. Especially people over the age of 65 account for 37.4 percent of total population in farming and fishing villages, the problem of a super-aged society is more serious than city. The Changes in Population Structure will raise complicated issues like decrease workforce and consumption, and finally undermine the country's growth potential and deteriorate the people's livelihood. Therefore, Using $\lceil$ The closed circulatory culture system on land $」$ can shorter working hours and participate in production activity, so retirement will be extended. In Oh Island, economic activity has been increased like processing, packaging, transportation, and accounting apart from 
abalone farming that using $\lceil$ The closed circulatory culture system on land $\rfloor$. Although $\mathrm{OH}$ Island abalone farming run a deficit, the Japanese government has to

\section{REFERENCES}

Kudo Takafumi. 2012. The Disadvantage Condition and the Problem of the Policy of the Isolated-island Fisheries. Journal of regional fisheries economy Vol. 52 No. 3, pp. 7-28 (in Japanese)

Rahman.m.m, kadowaki.s, linn,s.m, yamada.y. 2012. Land-Based Poly-Eco-Aquaculture of Abalone and Seaweed in a Small Scale Recirculating System Using a Recycled Freezer Container. Journal of Fisheries Technology, Vol. 35, pp. 77-84

Sasaki, Takafumi. 2012. Forms of Fishery that Facilitate Conservation in Unfavorable Fishing Places and Policy Problems : Based on the Symposium "The Present Conditions and Problems of Fishery in Isolated Islands". Journal of regional fisheries economy Vol. 52 No. 3, pp. 67-82 (in Japanese)

Takashi Fujimoto. 2015. Quantitative Analysis of the Regional Income Determinant Factors in a Remote Island Economy : Generation and Application of a Regional Input-Output Table. Journal of Rural Economics, Vol. 86 No. 4, pp. 257-272 (in Japanese)

Takashi Torii. 2012. Official Support for Fishery in Isolated Islands and Changes in Fishery Structure. Journal of regional fisheries economy Vol. 52 No. 3, pp. 29-46 (in Japanese) support agribusinessmen who aged 65 years old or older since Japan has became A superaged society and their primary industry is at risk of collapse. 